\title{
CONFERÊNCIA
}

\section{POLÍTICAS PÚBLICAS: possibilidades e potencialidades da educação integral'}

\author{
Cláudia da Mota Darós Parente²
}

\section{INTRODUÇÃO}

Nesta exposição, apresentamos algumas reflexões e proposições relativas à educação integral, à educação em tempo integral e à ampliação de oportunidades educativas, sobretudo a crianças, adolescentes e jovens em idade de escolarização obrigatória. Com isso, desejamos mobilizar e potencializar novos e contínuos movimentos e diálogos que contribuam para a formação humana com maior integralidade. Para isso, selecionamos alguns elementos principais advindos de minhas investigações realizadas nos últimos anos no campo de análise de políticas públicas e sobre políticas de educação integral em tempo integral.

Inicialmente, discorremos sobre a concepção de educação (integral), de modo a evidenciar sua construção sócio-histórica e cultural e as demandas formativas dirigidas às instituições sociais e, particularmente, à escola ao longo da história. A partir daí, criamos condições para entender como, historicamente, fomos demandando da escola certas funções sociais e como isso repercute na ação do Estado, cuja atuação ocorre por meio das políticas públicas. Sobre isso, achamos conveniente detalhar alguns aspectos do processo de constituição da política pública, do processo

\footnotetext{
1 Texto resultado da Conferência de abertura proferida no \|l Congresso Brasileiro de Educação Integral e IV Seminário Mineiro de Educação Integral, 10 de agosto de 2021.

${ }^{2}$ Doutorado em Educação na Universidade Estadual de Campinas (Unicamp); professora da Universidade Estadual Paulista (Unesp); Programa de Pós-Graduação em Educação (Unesp/Marília); Grupo de Pesquisa e Avaliação de Políticas Educacionais (GAPE). Orcid iD: http://orcid.org/0000-0003-0250-8935 E-mail: claudia.daros@unesp.br.
} 
decisório e das relações de força no âmbito do Estado, o que irá caracterizar o modo como opera, suas prioridades e, consequentemente, o desenho das políticas públicas.

$\mathrm{Na}$ exposição, apresentamos didaticamente dois desenhos de políticas públicas visíveis, possíveis e que podem coexistir: políticas de educação em tempo integral e políticas de ampliação de oportunidades educativas a crianças, adolescentes e jovens. Ao final, elencamos alguns elementos prospectivos diante do cenário atual, a fim de que seja possível avançarmos continuamente numa perspectiva que promova mais e melhores condições formativas, identificando caminhos, alternativas, possibilidades e potencialidades na construção de uma sociedade mais justa e humana.

\section{EDUCAÇÃO (INTEGRAL)}

Discorrer sobre políticas públicas e sua relação com a educação exige, primeiramente, demarcar nosso conceito de educação. Por detrás de todo fenômeno educativo existem concepções e a depender delas, produzimos determinadas formas de atuação no campo da educação.

Compreendemos a educação como processo que acontece com o ser humano ao longo de toda a vida e que envolve um conjunto de elementos: cognitivo, afetivo, psicológico, social, biológico, cultural, físico, político, moral, estético, intelectual, ético, espiritual etc. Porém, o processo educativo é um fenômeno complexo, assim como é complexo o ser humano. Determinado ato educativo pode mobilizar um ou mais elementos da formação humana. Porém, justamente por sua complexidade, o processo de formação humana deve ser visto como um continuum; não apenas ocorre ao longo de toda a vida, como também pode produzir respostas diferentes em sujeitos distintos e até mesmo respostas diferentes no mesmo sujeito, mas em momentos distintos. Assim, é improvável que um ato educativo mobilize simultaneamente todos os aspectos da formação humana, com resultados similares ao longo do tempo, em diferentes sujeitos e contextos e mediante ações e práticas de diversos agentes. 
Entretanto, de posse do conhecimento da complexidade do ser humano e da formação humana, podemos refletir sobre as possibilidades e potencialidades da educação no processo de constituição do ser humano. Há tempos, filósofos, antropólogos, sociólogos, pedagogos, entre muitos outros estudiosos, vêm oferecendo contribuições para pensarmos o fenômeno educativo e a formação humana.

No Brasil, há décadas, difundimos a expressão "educação integral" justamente para reforçar a intencionalidade de que 0 ato educativo contemple a integralidade dos elementos da formação humana. A necessidade de adjetivação ganha ainda mais força quando identificamos práticas educativas que tendem a esquecer certos aspectos da formação humana. Não é à toa que o termo "educação integral" se difundiu no começo do século XX, num contexto em que se desejava outra escola, que olhasse para o sujeito-aluno de uma forma diferente do que fazia a escola tradicional. Isso demarca que a concepção de educação e de escola são construções sócio-históricas e culturais, com heranças históricas, filosóficas e políticas advindas de diversas correntes teóricas.

Na atualidade, quando mencionamos o termo "educação integral", comumente, estamos defendendo o direito de todo ser humano a uma formação plena, abarcando seus vários aspectos, durante toda a vida. Ocorre que, desde finais do século XIX, em meio à formação dos Estados Nacionais e à disseminação da ideia de escola pública, gratuita e obrigatória, passamos a defender a instituição escolar como espaço privilegiado para a formação de crianças, adolescentes e jovens. Eis o motivo pelo qual, historicamente, passamos a depositar grande expectativa na escola pública, na educação estatal e nos profissionais da educação.

Conforme exposto, a educação (integral) envolve diferentes aspectos da formação humana e ocorre ao longo de toda a vida. Isso significa que a educação é resultado de diferentes agentes, processos, instituições e espaços, não se restringindo ao que denominamos educação formal.

Para fins meramente didáticos, longe de nos prendermos a limites conceituais estanques, amiúde fazemos uso de uma classificação que tenta 
abarcar as várias nuances do fenômeno educativo: educação informal, educação formal e educação não formal. A educação informal, caracterizada como não sistemática, ocorre ao longo de toda a vida, sobretudo no ambiente familiar, no trabalho, na comunidade e por intermédio dos meios de comunicação. A educação formal - organizada e sistemática - é representada pela instituição escolar, com seu currículo definido pelo Estado. Por fim, a educação não formal abrange inúmeras ações que ocorrem na sociedade, geralmente, em instituições ou movimentos sociais e que possuem um viés educativo, porém fora do sistema educacional (COOMBS; AHMED, 1974; TRILLA, 2000). Por meio dessa classificação, fica mais fácil visualizar a complexidade do fenômeno educativo com sua multiplicidade de processos, instituições, espaços e agentes.

No entanto, historicamente, centralizamos muitas demandas formativas na instituição escolar. A sociedade passou a requerer da escola certas funções sócio-educativas e culturais, ademais de certos resultados em relação ao processo formativo de seus sujeitos. Assim, é preciso entender que as funções que requeremos da escola são definições que afloram do próprio movimento histórico da sociedade, da educação, do conhecimento e das instituições sociais.

Compreender como as políticas públicas materializam respostas para que a escola cumpra suas funções sociais é uma das análises possíveis para entender em que medida a escola, o currículo escolar e os profissionais da educação atuam em prol da educação integral.

\section{POLÍTICAS PÚBLICAS}

Comumente, conceituamos políticas públicas como o Estado em ação, ou seja, as políticas públicas são a materialização da ação do Estado em resposta a determinada demanda ou problema social. Por esse prisma, as políticas públicas constituem-se um conjunto de ações que atuam como respostas materiais a certos problemas, questões e necessidades da 
sociedade em determinado momento histórico e espaço social (HÖFLING, 2001; HOWLET; RAMESH; PERL, 2013; SECCHI, 2014).

Assim, a política materializa as decisões do Estado, embora em cada governo, a depender da forma como se concebe a própria atuação do Estado e suas relações com a sociedade e com o mercado, haverá repercussões na forma, na abrangência e nas características das políticas públicas.

Analisar as políticas públicas é realizar um esforço de olhar de forma cuidadosa as ações do Estado. No campo da Ciência Política, estudiosos deixaram contribuições acerca de modelos, tipos e abordagens analíticas acerca da agenda, formulação, implementação e avaliação de políticas públicas (SOUZA, 2006; VIANA, 1996). No entanto, assim como a sociedade, o conhecimento transforma-se, o que requer continuamente novas abordagens, sistematizações e recursos para melhor compreender e/ou agir no mundo que nos cerca.

Quando nos aproximamos, então, de determinada política pública, podemos analisá-la a partir de diferentes prismas. Podemos fazer uma leitura de seus elementos prescritivos, de seus documentos normativos e de suas diretrizes. Com isso, é possível identificar os objetivos expressos de certa política, seus vínculos teórico-conceituais, entre outros elementos.

Mas é preciso estar ciente de que tais objetivos expressos dificilmente permanecerão tal qual foram concebidos, já que a racionalidade da política é limitada e é ingênuo pensarmos que a política é implementada tal qual foi formulada. Os objetivos e as diretrizes das políticas públicas são continuamente reformulados seja porque a sociedade e os sujeitos são diversos, seja porque a sociedade e os sujeitos resistem a determinadas ações e projetos definidos sem a sua participação e, cotidianamente, reinventam suas ações e revisam posições.

Transpondo esses conceitos para o contexto educacional, fica mais fácil entender - não necessariamente resolver - as questões que envolvem a dinâmica da política educacional, as temáticas que estão na agenda, as políticas públicas consolidadas em programas, projetos e ações em vigor, 
muitas das quais não obtêm resultados esperados. Nessa dinâmica de fazer política de forma enviesada e fragmentada, os educadores, à frente das práticas educativas, reiteradamente, mostram-se insatisfeitos com as inúmeras demandas que recaem sobre eles e com as pressões por resultados e respostas.

Quando sistematizamos certos modos de materialização da ação do Estado, conseguimos caracterizar e analisar o que denominamos "desenhos de políticas públicas". Assim, no que concerne à ação do Estado no âmbito da educação integral, para fins de exposição, podemos mencionar dois desenhos de políticas públicas que temos visto na atualidade: políticas de educação em tempo integral, com ações centradas na escola, num movimento crescente de envolver outros atores, processos, agentes, espaços e instituições em prol da educação integral; políticas de ampliação de oportunidades educativas a crianças, adolescentes e jovens, sendo a escola parte de um conjunto de agentes, espaços, processos e instituições em prol da educação integral. São desenhos que podem coexistir, ampliando as potencialidades da educação integral.

\section{POLÍTICAS DE EDUCAÇÃO EM TEMPO INTEGRAL}

Historicamente, O Estado definiu como sua a responsabilidade pela oferta da educação pública e gratuita. Isso significa que assumiu para si uma parcela de responsabilidade pela formação do ser humano. Atualmente, no Brasil, definimos a obrigatoriedade e a gratuidade da escolarização de crianças, adolescentes e jovens dos 4 aos 17 anos (BRASIL, 1996; 2009). Ou seja, delimitamos que um tempo e um espaço da formação humana é de responsabilidade do Estado. Estabelecer que o Estado deve oferecer educação gratuita e obrigatória é uma determinação legal que, na prática, é operacionalizada por meio de políticas públicas.

Assim, no que concerne à temática dos tempos escolares, quando o Estado determina que a criança fique na escola, há especificações relativas à obrigatoriedade desse tempo (escolarização obrigatória), ao tempo diário (jornada escolar), aos objetivos e às ações realizadas nesse tempo 
(currículo), aos responsáveis pela ação educativa (profissionais) e ao espaço da ação educativa. Esses elementos foram sendo definidos e revistos ao longo de nossa história; não são decisões permanentes, tomadas num único contexto histórico ou durante certo governo. Esses elementos demonstram que, em torno dos tempos escolares, são materializadas e estão interrelacionadas inúmeras políticas públicas: políticas de formação de professores, políticas de financiamento educacional, políticas curriculares, políticas de avaliação, políticas de educação em tempo integral etc. Justamente por isso, é importante que as políticas públicas e as decisões políticas sejam alvo de análises contínuas, inclusive para identificar continuidades, permanências, resistências e inovações ao longo da história da educação.

Costumamos afirmar que a temática da jornada escolar está na agenda das políticas públicas, ou seja, no conjunto das políticas educacionais, a discussão sobre a jornada escolar tem sido recorrente. No entanto, não significa que o Estado deva iniciar sua ação tendo como elemento a priori a jornada escolar. É preciso questionar se essa "ordem das coisas" tem ajudado ou prejudicado a ampliação de oportunidades educativas oferecidas a crianças, adolescentes e jovens, sobretudo àqueles em idade de escolarização obrigatória. Por isso, não se pode afirmar, peremptoriamente, que a educação em tempo integral deve ser oferecida para todos os alunos, sem antes definir a função social da escola, os princípios que a regem e o que se espera desse tempo ampliado.

No Brasil, o conceito de "escola de tempo integral" surgiu no começo do século XX em meio ao encurtamento da jornada escolar e à disseminação dos turnos escolares no contexto brasileiro. É, portanto, um conceito de escola que traz como elemento central o tempo e sua ampliação. Passamos a defender que mais tempo de escola poderia gerar mais oportunidades educativas aos alunos. A partir daí, passamos a ter escolas com jornadas parcial e/ou integral, o que remete a distintas configurações em relação ao tipo de jornada, tipo de atividade, espaços e agentes educativos. No contexto brasileiro, do ponto de vista legal, a 
jornada parcial é definida como aquela com o mínimo de 4 horas e a jornada integral como aquela com o mínimo de 7 horas (BRASIL, 1996).

Ao longo do século XX, vimos surgir escolas de tempo integral residualmente em certos cenários brasileiros, quase todas expressando intencionalidades em torno da educação integral, mas sendo formuladas e implementadas com fundamentos, perspectivas e abordagens bem diversas, resultados de inúmeras concepções não apenas pedagógicas, mas sobretudo políticas. Por isso, na análise de certas experiências, escolas e políticas, é preciso considerar objetivos expressos, fundamentos de base, teorias de fundo, intencionalidades mas, principalmente, as práticas sociais e educativas que se concretizaram efetivamente.

Em cada momento histórico e em cada cenário, a ampliação da jornada escolar teve certos objetivos, o que pode significar maior ou menor proximidade com a ideia e a prática da educação integral, não apenas do ponto de vista de seus objetivos anunciados, mas sobretudo de seus resultados objetivos. Os objetivos das políticas de ampliação da jornada escolar nem sempre foram os mesmos, inclusive porque a própria noção de educação integral também se modifica.

Principalmente a partir dos anos 2000, vimos surgir ações e políticas de ampliação da jornada escolar com novas características, o que nos levou a fazer uso de uma nova expressão: "educação em tempo integral" em lugar de "escola de tempo integral". A partir desse momento, ainda que a escola continuasse no centro da política pública, passou a se abrir a outros processos, agentes, instituições, espaços e profissionais, com vistas a oferecer mais e melhores oportunidades educativas aos seus estudantes.

No processo de formulação e implementação de políticas de educação em tempo integral, é preciso compreender o que mobiliza e conduz a ação do Estado. Se concebemos a educação como processo que abarca inúmeros elementos e durante toda a vida, devemos questionar: qual o papel do Estado na educação de crianças, adolescentes e jovens; em meio a outros espaços, instituições e atores que educam, qual o papel da escola; o que esperamos das instituições sociais de forma geral e, 
especificamente, da instituição escolar; o que esperamos da escola no tempo que os alunos permanecem nela; qual a função social da escola, do currículo escolar e suas contribuições para a educação integral.

A escola é uma construção social, assim como a função que exerce em cada tempo e em cada sociedade. E essa função social não é uma definição de gabinete ou proveniente de certas prescrições ou diretrizes, embora sofra impactos da forma como a política educacional opera, inclusive de determinações legais - igualmente resultado de forças e disputas políticas.

O fato é que existem muitas expectativas em relação à escola e muitas delas são resultado de um processo simplista de pensar a educação apenas sob o prisma da instituição escolar ou distanciado das transformações da sociedade e do conhecimento. Constantemente vivenciamos dilemas históricos, pedagógicos, políticos e filosóficos, o que impacta nos desenhos e nos objetivos das políticas públicas. Na delimitação das funções sociais da escola, muitas vezes seguimos rumo à "escola progressiva de educação integral" (TEIXEIRA, 1968), e nos deparamos com a "escola transbordante" (NÓVOA, 2009). Por isso, são muitos os riscos de requerer da escola mais do que ela pode dar ou de limitar sua ação a um caráter utilitarista frente às suas inúmeras potencialidades.

Nesse desenho de política pública, com centralidade na instituição escolar, O Estado precisa considerar os movimentos sociais, históricos, políticos e pedagógicos para oferecer respostas adequadas à sociedade. Ciente das necessidades e especificidades dos sujeitos da educação, o Estado deve definir os objetivos formativos da escola em determinado tempo sócio-histórico, estabelecendo os elementos da formação (currículo) e, consequentemente, o tempo necessário para que a formação almejada aconteça no âmbito da escola. Afinal, quando ampliamos a jornada escolar, estamos ampliando o quê? Estamos oferecendo mais tempo na escola para o aluno fazer o quê? Queremos um currículo escolar ampliado envolvendo quais conhecimentos, atividades, ações e sujeitos? 
A análise de diferentes políticas e práticas nacionais e internacionais de organização e ampliação da jornada escolar, inclusive em diferentes momentos históricos, tem gerado um conjunto de elementos analíticos que nos ajudam a entender suas características e especificidades na atualidade (PARENTE, 2016; 2020a; 2020b; 2021). Ademais, apontam algumas possibilidades no campo da organização curricular. Assim, temos visto políticas públicas que, ao ampliarem o tempo do aluno na escola, promovem distintas formas de organização curricular: atividades extracurriculares integradas ao currículo escolar; atividades extracurriculares na escola; atividades extracurriculares em instituições socioeducativas ou outros espaços públicos e privados.

Portanto, no desenho de políticas de educação em tempo integral é necessário tomar decisões políticas importantes. No que se refere ao currículo, deve-se questionar se esse tempo ampliado abrangerá atividades curriculares e/ou extracurriculares, inclusive considerando as transformações conceituais de currículo no tempo e no espaço. No que tange aos profissionais da educação, deve-se indagar sobre os responsáveis pela ação educativa, inclusive concebendo as transformações que envolvem esse conceito do ponto de vista legal, social, político e pedagógico. Quanto ao espaço da ação educativa, deve-se questionar se essas ações ocorrerão apenas na escola ou abarcarão espaços escolares e não escolares. Do ponto de vista do financiamento da política pública, será necessário definir até onde vai a responsabilidade do Estado, o que remete novamente ao que cabe à escola pública e ao currículo escolar, em meio a outras instituições, espaços, processos e agentes educativos.

\section{POLÍTICAS PÚBLICAS DE EDUCAÇÃO INTEGRAL A CRIANÇAS, ADOLESCENTES E JOVENS}

Como analistas de políticas públicas, pesquisadores e educadores, precisamos aproveitar que a discussão sobre a jornada escolar está na agenda política e produzir reflexões e ações, a fim de que o papel do Estado seja mais efetivo não apenas na área educacional, mas na 
sociedade de forma geral, de modo a aproveitar todos os recursos disponíveis e colocá-los a serviço da educação integral, especialmente, de crianças, adolescentes e jovens, foco desta exposição.

Infelizmente, muitas políticas públicas são formuladas de forma compartimentada, setorizada, parcializada, herança da forma como pensamos a sociedade, o conhecimento e o ser humano. Essa forma compartimentada de compreender a sociedade, o conhecimento, o ser humano e, especificamente, as políticas públicas traz consequências para o modo como o Estado responde às demandas sociais, ou seja, nem sempre de maneira articulada, englobando os mais diferentes aspectos da sociedade e do ser humano. Inclusive, essa forma de responder às demandas sociais pode causar desperdícios em termos de recursos físicos, financeiros, materiais e humanos.

Assim, nos distintos âmbitos do Estado, nas esferas governamentais, vemos políticas públicas setoriais de educação, saúde, cultura, assistência social, esporte etc. Mas será que a ação do Estado nessas áreas tem sido efetiva?

Para desenhar políticas públicas que estejam a serviço da educação integral, precisamos ter como elemento a priori os sujeitos da educação, ou seja, nossas crianças, adolescentes e jovens. Assim, as políticas públicas precisam conhecer e reconhecer suas necessidades, seus modos de vida e a realidade em que vivem. No contexto atual, é necessário ressaltar a multiplicidade de infâncias, adolescências e juventudes, ou seja, sujeitos que vivem em condições sociais, econômicas, sociais e culturais bem diversas, muitos dos quais em situações bem difíceis e muito distantes das concepções de educação integral e, consequentemente, de justiça, igualdade, equidade e humanidade.

Nesse cenário, vimos nascer várias políticas embasadas em certos fundamentos: articulação entre educação formal e educação não formal, ideia de cidade educadora, noção de território educativo, noção de intersetorialidade, enfoque de relações intergovernamentais e abordagem de redes de políticas (PARENTE, 2020b). Esses fundamentos explicam as 
opções político-pedagógicas que foram sendo tomadas para a formulação e implementação de políticas públicas em certos contextos nacionais e internacionais para melhorar a educação integral de crianças, adolescentes e jovens.

Como o Estado ainda se organiza de forma setorial, formular e implementar políticas públicas intersetorialmente, abrangendo diferentes aspectos da formação humana constitui-se excelente oportunidade para que os setores dialoguem, se articulem e se redescubram tão próximos que até mesmo deixem de existir.

À medida que o Estado revê seu foco de ação e prioriza os sujeitos da educação e a formação humana, promove um movimento profícuo em torno do planejamento e da gestão da política pública, repercutindo nas relações do Estado com a sociedade e oferecendo melhores respostas aos problemas e demandas sociais.

\section{CENÁRIO E HORIZONTES}

A temática da educação integral possui inúmeras nuances e perspectivas de análise. Nesta exposição, elencamos alguns elementos que visualizamos serem fundamentais nas relações entre educação integral e políticas públicas na atualidade.

Além dos aspectos destacados, é importante mencionar que o cenário da pandemia por Covid-19 acentuou ainda mais as desigualdades já existentes. Não só ficamos impossibilitados de oferecer uma formação integral, como, em vários contextos, sequer foi oferecido qualquer tipo de formação a crianças, adolescentes e jovens.

Diante do cenário atual, algumas recomendações e expectativas. É essencial acentuar o debate da educação integral, abrangendo novas perspectivas, abordagens e aspectos da formação humana e das políticas públicas. É preciso valorizar a escola e identificar recursos e formas para que cumpra seu papel social, resistindo a utilitarismos e excessos, a fim de que 
não seja culpabilizada por elementos estruturais que antecedem sua tarefa educativa.

Por isso, é fundamental pensar em como vamos organizar espaços, instituições, recursos e processos, mobilizando educadores e instituições para a formulação de estratégias e alternativas que deem conta de uma formação humana integral, consolidando políticas públicas para a formação de crianças, adolescentes e jovens em processo de escolarização obrigatória. Para isso, é preciso avaliar continuamente as ações do Estado, de modo a verificar o que estamos fazendo e o que precisamos fazer para avançarmos rumo a uma política de educação integral mais próxima de nossas concepções e ideais.

\section{REFERÊNCIAS}

BRASIL. Emenda Constitucional n. 59, de 11 de novembro de 2009. [...] dá nova redação aos incisos I e VII do art. 208, de forma a prever a obrigatoriedade do ensino de quatro a dezessete anos [...]. Disponível em: http://www.planalto.gov.br/ccivil_03/constituicao/Emendas/Emc/emc59.htm \#art6 Acesso em: 30 out. 2021.

BRASIL. Lei n. 9.394, de 20 de dezembro de 1996. Estabelece as diretrizes e bases da educação nacional. Disponível em:

http://www.planalto.gov.br/ccivil_03/leis/19394.htm. Acesso em: 30 out. 2021.

COOMBS, P. H. T.; AHMED, M. Attacking rural poverty: how nonformal education can help. Baltimore: London: Johns Hopkins University Press, 1974.

HÖFLING, E. Estado e políticas (públicas) sociais. Cadernos Cedes, Campinas, v. 21, p. 30-41, 2001.

HOWLETT, M.; RAMESH, M.; PERL, A. Política Pública: seus ciclos e subsistemas uma abordagem integradora. Rio de Janeiro: Elsevier, 2013.

NÓVOA, A. Professores: o futuro ainda demora muito tempo. Lisboa: EDUCA, 2009.

PARENTE, C. M D. Análise comparada da jornada escolar em países da União Europeia. Cadernos de Pesquisa, São Paulo, v. 50, n. 175, p. 78-95, jan./mar. 2020. 
PARENTE, C. M D. Construindo uma Tipologia das Políticas de Educação Integral em Tempo Integral. Roteiro, Joaçaba, v. 41, n. 3, p. 563-586, set./dez. 2016.

PARENTE, C. M D. Políticas de ampliação da jornada escolar: fundamentos e proposições. Roteiro, v. 45, p. 1-26, 2020 b.

PARENTE, C. M D. Políticas de educação integral em tempo integral: possibilidades e alternativas. In: PARENTE, C. M D. (org.). Políticas públicas para a educação básica: avanços, desafios e perspectivas. Marília: Oficina Universitária; São Paulo: Cultura Acadêmica, 2021. p. 97-123.

SECCHI, L. Políticas Públicas: conceitos, esquemas de análise, casos práticos. São Paulo: Cengage Learning, 2014.

SOUZA, C. Políticas Públicas: uma revisão da literatura. Sociologias, Porto Alegre, v. 8, n. 16, p. 20-45, jul./dez 2006.

TEIXEIRA, A. Pequena introdução à filosofia da educação: a escola progressiva ou a transformação da escola. 5 ed. São Paulo: Cia. Editora Nacional, 1968.

TRILLA, J. La cultura y sus mediaciones pedagógicas. In: GARRIDO, J. L. (coord.). La sociedad educadora. Madrid: Fundación Independiente, 2000. p. 125-144.

VIANA, A. L. Abordagens Metodológicas em Políticas Públicas. Revista Brasileira de Administração Pública, Rio de Janeiro, v. 30, n. 2, p. 5-43, mar./abr. 1996.

Recebido em: 01 de outubro de 2021. Aprovado em: 03 de novembro de 2021. Publicado em: 03 de novembro de 2021. 